\title{
Distinct Reproductive Types of Male Spider Crabs Libinia emarginata Differ in Circulating and Synthesizing Methyl Farnesoate
}

\author{
AMIR SAGI ${ }^{1}$, ELLEN HOMOLA ${ }^{2}$, AND HANS LAUFER ${ }^{3}$ \\ Department of Molecular and Cell Biology, University of Connecticut, Storrs, Connecticut 06260 and \\ Marine Biological Laboratory, Woods Hole, Massachusetts 02543
}

\begin{abstract}
Levels of methyl farnesoate in the blood and in vitro rates of methyl farnesoate synthesis by the mandibular organ were investigated to determine whether this compound is related to the differences in morphology and reproductive states of distinct types of male spider crabs described by Homola et al. (1992) in winter populations. Three male types, selected from a summer population, were investigated in detail: (1) males with relatively large propoduses (claws) and worn exoskeletons (abraded), (2) males with relatively large propoduses and exoskeletons covered with epicuticle (unabraded), and (3) males with small propoduses and unabraded exoskeletons (small).

All males examined had sperm, but abraded males, identical in propodus and body size to unabraded males, had a reproductive system that weighed twice as much. Large-clawed unabraded males had relatively small reproductive systems. Small-clawed males possessed a small reproductive system.

$\Lambda$ braded males possessed larger mandibular organs, containing almost twice the total protein, and their mandibular organs synthesized significantly more methyl farnesoate in vitro than did the other types of males. Circulating levels of methyl farnesoate, in the hemolymph of the abraded males, were more then twice as high as the levels detected in any other type of male.
\end{abstract}

Received 12 August 1991; accepted 16 July 1993.

${ }^{1}$ Present address: Department of Life Sciences, Ben-Gurion University, P.O. Box 653, Beer-Sheva, 84105, Israel.

${ }^{2}$ Present address: Bodega Marine Laboratory, University of California, P.O. Box 247, Bodega Bay, CA 94923.

${ }^{3}$ To whom all correspondence should be addressed.

Abbreviations: A, abraded; U, unabraded; S, small; MF, methyl farnesuate.
The strong relationship between methyl farnesoate levels, male morphology, and reproductive system development calls for further studies on the role of methyl farnesoate in the regulation of reproduction and morphogenesis in male crustaceans.

\section{Introduction}

The crustacean mandibular organ was first described by Le Roux (1968). Two decades later, Laufer et al. (1987) identified a secretory product of this gland, methyl farnesoate, which is found both in the mandibular organ and the hemolymph of the spider crab $L$. emarginata. Methyl farnesoate is the unepoxidated form of the insect juvenile hormone III. In insects, juvenile hormones play several regulatory roles both as gonadotropins (Herman and Bennett, 1975) and morphogens (Wigglesworth, 1970).

Different male types were described in adult spider crab populations using a propodus (claw) to carapace ratio (Tessier, 1960; Hartnoll, 1963; Aldrich, 1974). Recently, different adult male types were described in L. emarginata that were collected in the winter (Homola et al., 1992). Those types differ from each other in the appearance of the exoskeleton as well as in relative claw size. Abraded males had larger reproductive systems and higher methyl farnesoate titers compared to the unabraded males (Homola et al., 1992).

The present study examines the size of the mandibular organ, its relative rate of methyl farnesoate synthesis, and level of methyl farnesoate in the circulatory system of $L$. emarginata males collected in the summer. We report the results of a comparative study of methyl farnesoate production and circulation in threc malc morphs distinctive 
in their claw size, appearance of the exoskeleton, and development of their reproductive system.

\section{Materials and Methods}

\section{Animals}

Individuals of Libinia emarginata were collected in two locations, off the coast $2 \mathrm{~km}$ south of Woods Hole, Massachusetts, and $1 \mathrm{~km}$ north of Vineyard Haven harbor, Martha's Vineyard, during June and July 1990. Two hundred and four (204) male crabs were individually tagged and held in the facilities of the Marine Biological Laboratory (Woods Hole, MA) in two 4500-liter tanks in the presence of females. Fresh seawater was continuously pumped into the tanks so that the whole volume of water was replaced 2.5 times a day. The crabs were fed fresh or frozen squid twice a day ad libitum. Leftover food and other debris was siphoned out of the tanks once a day. Carapace length and propodus length were measured to the nearest millimeter using a vernier caliper. The animals were categorized into three morphs on the basis of $\log$ propodus to $\log$ carapace ratios, and the appearance of the exoskeleton (Tessier, 1960; Kuris et al., 1987; Homola et al., 1992). The abraded and unabraded morphs were illustrated previously (Homola et al., 1992). Because L. emarginata molt in the fall (Hinsch, pers. comm., Hinsch, 1972) and newly molted animals are completely unabraded, the unabraded males collected in the summer had more variation in the state of abrasion of the carapace compared with the winter population (Homola et al., 1992). Therefore the population was classified with respect to the degree of abrasion, and animals with the greatest amount of intact epicuticle were selected and classified as unabraded males. Three distinct types of males were selected from the captured population of 204 males shown in Figure 1: (1) abraded large males (A) with relatively large propodus $(n=20)$, (2) unabraded large males $(\mathrm{U})$ with relatively large propodus $(\mathrm{n}=20)$, and (3) unabraded males with a relatively small propodus $(\mathrm{S})(\mathrm{n}$ $=29$ ).

\section{The reproductive system of selected male types}

Body weight was measured to $\pm 0.01 \mathrm{~g}$. The testes, sperm duct, and accessory gland (Homola et al., 1992) were dissected and weighed separately to $\pm 0.01 \mathrm{~g}$ to determine their wet weight. The reproductive system indices were calculated by dividing the sum of the components of the reproductive system by carapace length and multiplying by 100 . A sample of semen from the vas deferens of each crab was examined under a light microscope for the presence of spermatophores.
In vitro methyl farnesoate synthesis by the mandibular organ

The paired mandibular organs were dissected from each male. One organ was removed from the mandibular tendon, homogenized in Pantin's saline (Laufer et al., 1986, 1987), and an aliquot was withdrawn for total protein determination, using the Bradford protein assay (Bradford, 1976). The other organ was incubated attached to the mandibular tendon, so that it would not be damaged during dissection, and transferred to $400 \mu \mathrm{l}$ of media where it was incubated for $2 \mathrm{~h}$ at $22-25^{\circ} \mathrm{C}$ with gentle agitation. The culture medium was Pantin's saline containing 20 $\mathrm{m} M$ HEPES (pH 7.4), $3.8 \mathrm{~m} M$ dextrose, $0.2 \%$ BSA and $\left[\right.$ methyl ${ }^{3}$ ]-methionine (specific activity $=200 \mathrm{mCi}$ / mmole, total activity $=40 \mu \mathrm{Ci} / \mathrm{ml}$ ). Following incubation, the isotope incorporation was stopped by fixing the cells with ethanol. The gland and the culture medium were then homogenized and extracted with $1 \mathrm{ml}$ hexane. Therefore, MF synthesis refers to the sum of the radiolabeled MF secreted into the medium and that which is retained within the gland. The amount of radioactivity in methyl farnesoate in a $100 \mu \mathrm{l}$ sample was determined using liquid scintillation spectrometry. Approximately $90 \%$ of the radioactivity in the hexane extract co-eluted with the methyl farnesoate standard on normal phase HPLC (Laufer and Borst, 1988; Homola, 1989).

\section{Methyl farnesoate levels in the hemolymph}

Prior to dissection, hemolymph samples $(2 \mathrm{ml})$ were taken from the base of the walking legs, using a 5-cc syringe with an 18-gauge needle. The samples were transferred to $15-\mathrm{ml}$ glass tubes, on ice, containing $5 \mathrm{ml}$ acetonitrile, and $2 \mathrm{ml} \mathrm{4 \%} \mathrm{NaCl} .25 \mathrm{ng}$ of the cis-trans (non-biological) isomer of methyl farnesoate was added to each tube as an internal standard (Sagi et al., 1991). The samples were extracted with $1 \mathrm{ml}$ hexane. Hemolymph titers of methyl farnesoate were determined according to the method developed by Laufer et al. $(1986,1987)$ and modified by Borst and Tsukimura (1991). Two hundred microliters from the hexane phase was loaded onto a Waters HPLC system using a $5 \mu$ Econosil silica column (Alltech), two model 501 pumps and a Lambda Max 481 absorbance detector that was set at $218 \mathrm{~nm}$. The running solvent was $1 \%$ diethyl ether in hexane flowing at $2.5 \mathrm{ml} / \mathrm{min}$. Peak areas were calculated using Omega software (Version 1.4 Perkin Elmer/Nelson), and hemolymph methyl farnesoate titers were determined with reference to the known amount of the internal standard in the sample.

\section{Data analysis}

The dimensions in $\mathrm{mm}$ of the propodus along the lateral margin, and the length of the carapace, were logarith- 


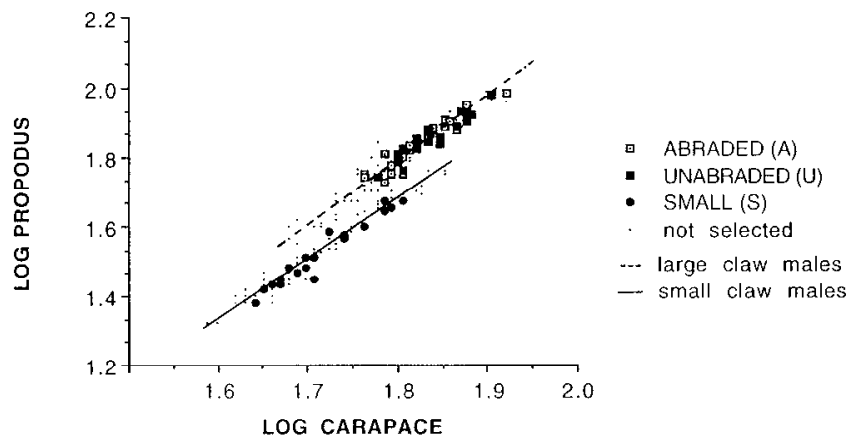

Figure 1. Regression analysis of log-transformed carapace and propodus data from a summer population of male Libinia emarginata. Three male types were found in the sample: abraded $(\square)$ and unabraded (ロ) males with relatively large propoduses (the upper regression line) and small claw type (๑) (the lower regression line). Animals marked not selected (.) were present in the original sample but not used in this study.

mically transformed prior to the analysis of linear regression (Tessier, 1960; Kuris et al., 1987). Assuming that the specific activity of the radiolabeled methyl farnesoate synthesized by the gland is equal to that of the precursor, and that only one labeled methyl group is incorporated into each methyl farnesoatc molcculc, the in vitro synthetic rates of the mandibular organs were calculated and expressed in nanomoles/gland/h as was previously calculated for Libinia emarginata (Laufer et al., 1987) and Procambarus clarkii glands (Landau et al., 1989).

Pearson correlation coefficients and Waller-Duncan kratio $t$ test were calculated using the Statistical Analysis System (SAS Institute, Cary, North Carolina).

\section{Results}

\section{T'ypes of male L. emarginata}

Males (204 individuals), with carapace length greater than $35 \mathrm{~mm}$, were plotted with respect to $\log$ propodus versus log carapace (Fig. 1). The population appears to fall into two linear clusters (Homola et al., 1992). The upper regression line represents the large-clawed males while the lower regression line represents unabraded smallclawed males (S). Among the large-clawed males, two distinct classes emerged with respect to exoskeleton texture. Abraded males (A) were quite smooth and were presumed to have molted a long time ago; unabraded males (U) had velvety epicuticle and presumably molted the previous fall.

Reproductive system and mandibular organ size in the different types of males

The three morphologically distinct male types differ in the relative development of their reproductive systems and mandibular organs (Fig. 2). The largest reproductive

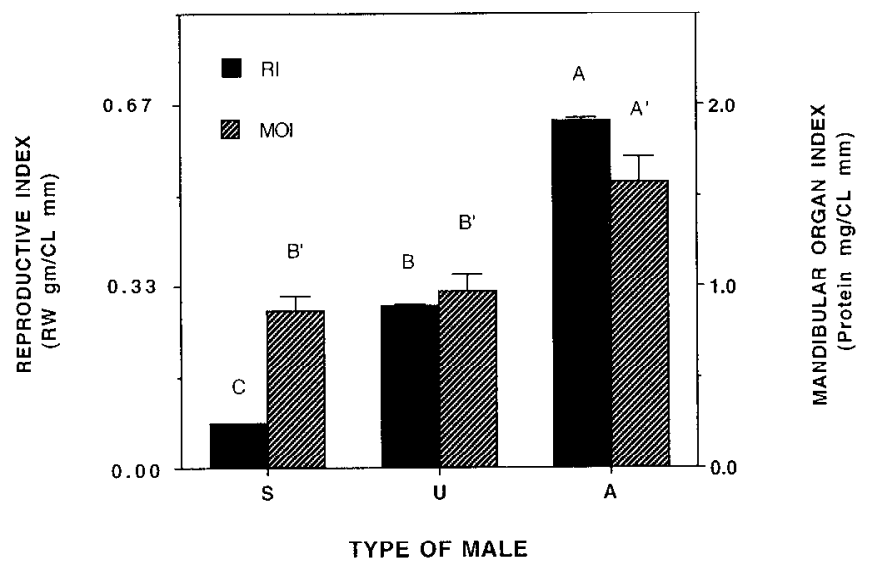

Figure 2. The reproductive system and mandibular organ indices in the three types of Libinia emarginata males. Abraded (A), unabraded $(\mathrm{U})$, and small-clawed (S). Reproductive system weight (RW), carapace length (CL), reproductive index (RI), mandibular organ index (MOI). The reproductive system weight was normalized for body size and the mandibular organ index is expressed as total mandibular organ protein normalized for body size. Bars represent mean \pm SEM of at least 17 observations. Bars labeled with different letters are significantly different $(P \leq 0.001)$.

system and mandibular organ indices (normalized for body size), were found in the abraded males $(0.64 \pm 0.2$ and $1.51 \pm 0.77$, respectively). The reproductive system and mandibular organ indices were significantly lower in the unabraded males $(0.3 \pm 0.1$ and $0.97 \pm 0.43$, respectively) and were the lowest in the small-clawed unabraded males $(0.08 \pm 0.01$ and $0.87 \pm 0.35$, respectively). Mandibular organ indices were not statistically different in small clawed and unabraded males. The size of the reproductive system (Fig. 3) and mandibular organ (Fig. 4)

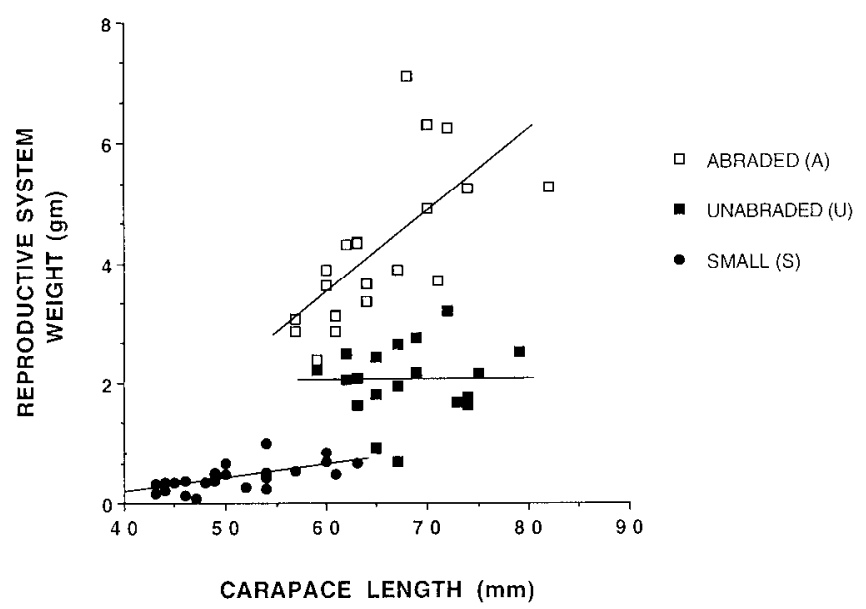

Figure 3. Regression analysis of carapace length and reproductive system weight in the three types of Libinia emarginata males. Abraded (A) $(\mathrm{y}--4.61 \pm 0.14 \mathrm{x})$, unabraded $(\mathrm{U})\left(\mathrm{y}=1.98 \pm 1.09 \times 10^{-3} \mathrm{x}\right)$, and small-clawed $(\mathrm{S})\left(\mathrm{y}=-0.71 \pm 2.26 \times 10^{-2} \mathrm{x}\right)$. 


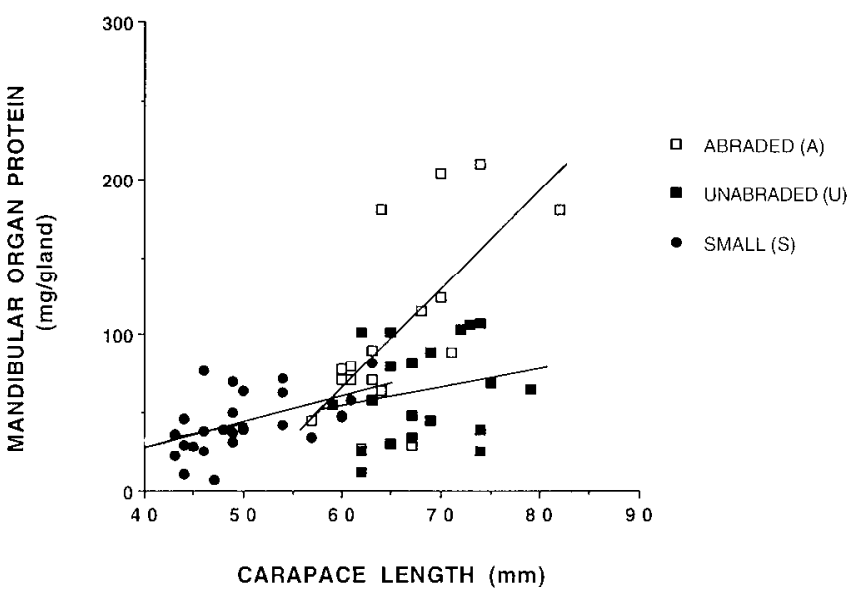

Figure 4. Regression analysis of carapace length and total protcin in the mandibular organ of three Libinia emarginata male types. Abraded (A) $(y=-313.96 \pm 6.32 x)$, unabraded (U) $(y=-17.27 \pm 1.19 x)$, and small-clawed $(\mathrm{S})(\mathrm{y}=-38.7 \pm 1.65 \mathrm{x})$.

appear to be significantly correlated with body size in both the abraded (A) and small-clawed (S) males. The Pearson correlation coefficients for reproductive systems and carapaces are: $\mathrm{A}, \mathrm{r}=0.683 P \leq 0.001 \mathrm{n}=20, \mathrm{~S}, \mathrm{r}=0.623$ $P \leq 0.001 \mathrm{n}=29$, and for the mandibular organs and carapaces $\mathrm{A}, \mathrm{r}=0.676 P \leq 0.002 \mathrm{n}=17 ; \mathrm{S}, \mathrm{r}=0.513 P$ $\leq 0.007 \mathrm{n}=26$. In the unabraded males, the sizes of the mandibular organ and the reproductive system were not found to be significantly correlated with body size, Pearson correlation coefficients for reproductive system and carapace $r=0.080 P \leq 0.73 \mathrm{n}=20$, and for the mandibular organ and carapace $\mathrm{r}=0.126 P \leq 0.600 \mathrm{n}=19$.

\section{Methyl farnesoate synthesis and its levels in the circulation}

The largest mandibular organs, i.e., those having the highest measurements of total protein per gland (Fig. 5), were found in the abraded males $(101.62 \pm 58.43 \mathrm{mg})$. The largest glands synthesized the highest amounts of methyl farnesoate during a $2-\mathrm{h}$ incubation period $(9.3$ $\times 10^{5} \pm 4.8 \times 10^{5} \mathrm{DPM}$ in methyl farnesoate/gland $/ 2 \mathrm{~h}$ or $1.04 \pm 0.54$ nanomoles/gland/h). The smaller glands $(66.65 \pm 29.29 \mathrm{mg})$ of the unabraded males synthesized significantly less methyl farnesoate in vitro $\left(5.7 \times 10^{5} \pm 2.4\right.$ $\times 10^{5} \mathrm{DPM} /$ gland/2 $\mathrm{h}$, or $0.64 \pm 0.27$ nanomoles/ gland/h), and the small mandibular organs (43.94 \pm 19.06 $\mathrm{mg}$ ) of the small clawed males synthesized the smallest amounts of methyl farnesoate $\left(3.3 \times 10^{5} \pm 2.0 \times 10^{5}\right.$ DPM/gland/ $2 \mathrm{~h}$, or $0.37 \pm 0.22$ nanomoles/gland/h).

The circulating levels of methyl farnesoate (Fig. 6) were the highest in the abraded males $(67.20 \pm 16.58 \mathrm{ng} / \mathrm{ml})$. Methyl farnesoate levels were significantly lower in the hemolymph of the unabraded males $(29.60 \pm 7.10 \mathrm{ng} /$

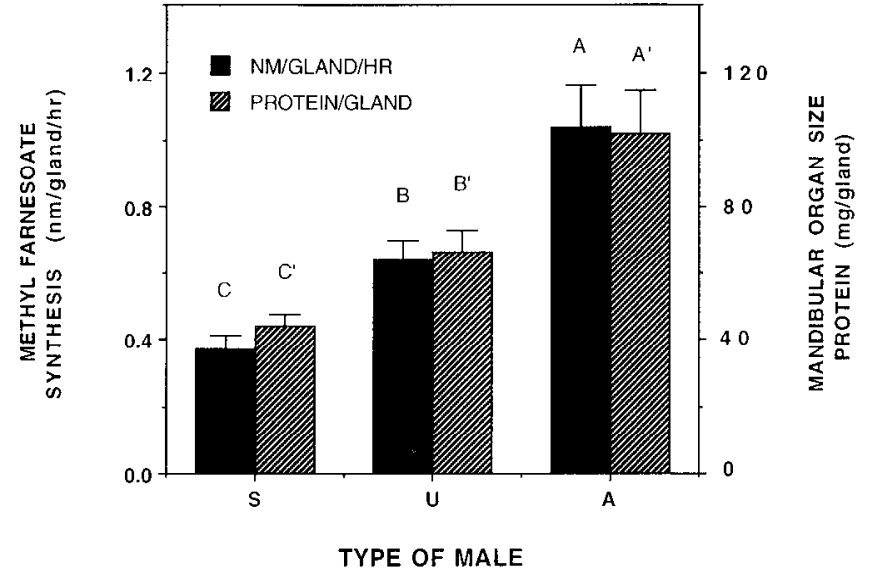

Figure 5. Mandibular organ size and its in vitro methyl farnesoate synthesis in three Libinia emarginata male types. Abraded (A), unabraded (U), and small-clawed (S). Mandibular organ size is expressed in total (mg) protein per gland and its activity is measured by the amount of radiolabeled methyl farnesoate produced by an organ within a one-hour period. The bars represent mean \pm SEM of at least 17 observations. Bars labeled with different letters are significantly different $(P \leq 0.001)$.

$\mathrm{ml}$ ), despite the fact that these males had similar claw and carapace sizes as did the abraded males. The lowest level of methyl farnesoate was found in the hemolymph of small-clawed males $(10.70 \pm 5.97 \mathrm{ng} / \mathrm{ml})$, this value is not statistically different from the level found in the large unabraded males.

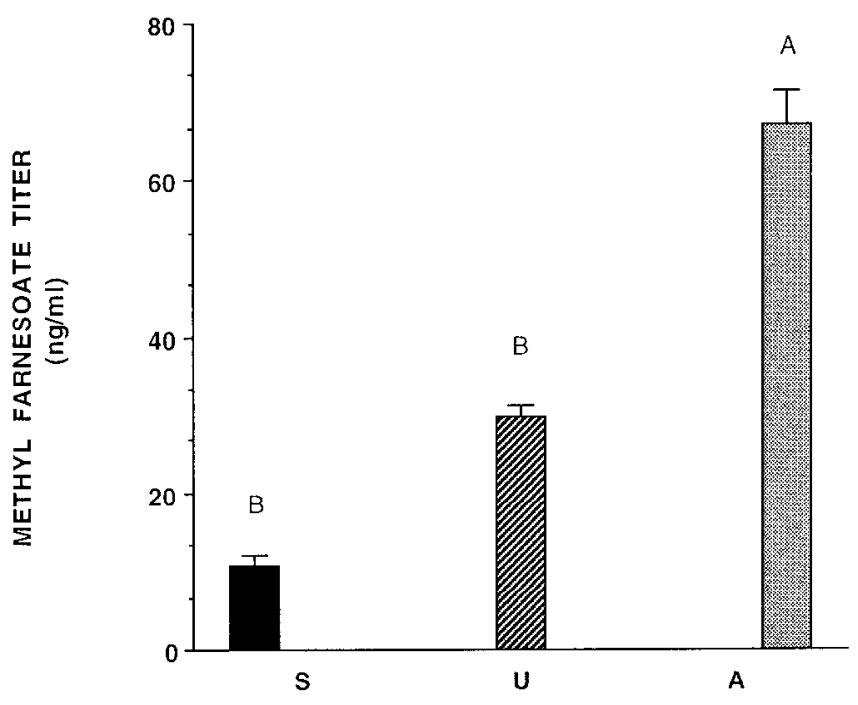

TYPE OF MALE

Figure 6. Circulating levels of methyl farnesoate in the hemolymph of three Iibinia emarginata male types. Abraded (A), unabraded (U), and small-clawed (S). Methyl farnesoate concentrations are expressed in $\mathrm{ng} / \mathrm{ml}$ of hemolymph. The bars represent mean \pm SEM of at least 17 observations. Bars labeled with different letters are significantly different $(P \leq 0.001)$. 


\section{Discussion}

Distinct male L. emarginata morphs

Hartnoll (1963) described three types of male spider crabs on the basis of relative claw length. We suggest, on the basis of differences in the appearance of the exoskeleton, that the 'mature' (Hartnoll, 1963) type is composed of two distinct types, unabraded and abraded males (Homola et al., 1992). These male morphs may represent different reproductive states within the life history of $L$. emarginata. This vicw is supported by the fact that the reproductive systems and the mandibular organs are considerably less developed in unabraded males compared with abraded males of the same size. Males with relatively small propoduses were termed 'pre-pubescent' by Hartnoll (1963). We found such males to posses mature sperm and thus 'pre-pubescent' is physiologically inappropriate; we used the term small-claw male. In the present study we did not investigate smaller males that were termed 'immature' by Hartnoll and may posses different morphological features. This fraction of the population remains to be studied in the future.

\section{The life history of male $\mathbf{L}$. emarginata}

The relation of epicuticular loss and reproductive system growth illuminates our understanding of the life history of $L$. cmarginata. Our observations of winter populations (Homola et al., 1992) and the observations by Hinsch (pers. comm. and Hinsch, 1972) that large $L$. emarginata males terminally molt in the fall, suggests to us that the abraded crabs investigated are anecdysic and that they last molted two seasons ago approximately 20 months prior to the study (or earlier). Thus, these males have reached full reproductive tract development, positively related to their body size, at least a year following their terminal molt. On the other hand, the unabraded large-clawed males, having similar body sizes but significantly smaller reproductive systems and mandibular organs, are suggested to have had their terminal molt approximately 11 months ago in the previous fall. Unlike the abraded males, the sizes of the mandibular organs and the reproductive tracts in the unabraded males are poorly correlated with body size. The reproductive indices of unabraded males collected in the summer were twice as large as those collected in the winter ( 1.19 and 0.58 , respectively; Homola et al., 1992). Correspondingly, methyl farncsoatc titers increased from $5.2 \mathrm{ng} / \mathrm{ml}$ in the winter (Homola et al., 1992) to $29 \mathrm{ng} / \mathrm{ml}$ in the summer. The facts that (a) the reproductive system of the unabraded male is not as fully developed as is permitted by its body size, (b) their reproductive system is much smaller than the abraded males of the same body size, and (c) their reproductive system indices increased from winter to summer, may indicate that unabraded males are either in the process of commencement of reproductive augmentation, or are under a state of reproductive arrest.

\section{Possible role for methyl farnesoate in the regulation of reproduction and morphogenesis}

The fact that gonadal maturity and high methyl farnesoate synthesis by the mandibular organ and elevated methyl farnesoate in the blood coincide in male Libinia emarginata may suggest that all three events occur in parallel due to a higher causal regulation and are thus related, but independent events. It may also suggest a causal relationship, comparable to juvenile hormone and reproduction in insects (Herman and Bennett, 1975; Wigglesworth, 1970). This relationship is suggested by the fact that the most active mandibular organs are in males with the highest levels of methyl farnesoate in their hemolymph, and that these males have the most highly developcd reproductive systcms. Morcover, Hinsch (1980) observed that gonad size is stimulated by mandibular organ implants. Because methyl farnesoate is the predominant product of the mandibular organ, it is suggested that the relationship between this compound and the gonad index may be viewed as causal. Along these lines it can be suggested that in these crabs, methyl farnesoate may act similarly to juvenile hormone in several insect species, by terminating reproductive diapause and stimulating reproduction (Spielman, 1974; Mitchell, 1981; De Wilde, 1983, for review). The results of the present study call for future direct experimental approach, such as mandibular organ transplantation or methyl farnesoate augmentation, in order to study the causal relationship between methyl farnesoate levels and reproduction.

\section{Acknowledgments}

We thank Dr. Armand Kuris for numerous stimulating discussions and Dr. Jonna Ahl for her critical review of the manuscript. We also thank Dr. Frank Mauri from the Biotechnology Center of the University of Connecticut for his technical advice, and David Koslowsky and Hadi Danai for their assistance. This study was supported by a U. S. Israel Binational Agricultural Research and Development fellowship and by a Fulbright fellowship (to A.S.) and the Sea Grant College program (NOAA), a Research Service Award from the NIH and a Lady Davis fellowship (to H.L.).

\section{Literature Cited}

Aldrich, J. C. 1974. Allometric studies on energy relationships in the spider crab Libinia emarginata (Leach). Biol. Bull. 147: 257-273.

Borst, D. W., and B. Tsukimura. 1991. Quantification of methyl farnesoate levels in hemolymph by high-performance liquid chromatography. J. Chromatogr. 545: 71-78. 
Bradford, M. 1976. A rapid and sensitive method for the quantification of microgram quantities of protein utilizing the principle of proteindye binding. Anal. Biochem. 72: 248-254.

De Wilde, J. 1983. Endocrine aspects of diapause in the adult stage. Pp. 357-368 in Invertebrate Endocrinology, Vol. 1, R. G. H. Downer and H. Laufer, eds. A. R. Liss, Inc., New York.

Hartnoll, R. G. 1963. The biology of Manx spider crabs. Proc. Zool. Soc. Lond. 141: 423-496.

Herman, W. S., and D. C. Bennett. 1975. Regulation of oogenesis, female-specific protein production, and male and female reproductive gland development by juvenile hormone in the butterfly, Nymphalis antiopa. J. Comp. Physiol. 99: 321-338.

Hinsch, G. W. 1972. Some factors controlling reproduction in the spider crab Libinia emarginata. Biol. Bull. 143: 358-366.

Hinsch, G. W. 1980. Effect of mandibular organ implants upon the spider crab ovary. Trans. Am. Microsc. Soc. 99: 317-322.

Homola, E. M. 1989. Regulation of methyl farnesoate synthesis in the spider crab, Libinia emarginata. M. S. Thesis. University of Connecticut. $85 \mathrm{pp}$.

Homola, E., A. Sagi, and H. Laufer. 1991. Relationship of claw form and exoskeleton condition to reproductive system size and methyl farnesoate in male spider crab Libinia emarginata. Invert. Reprod. Dev. 20: 219-225.

Kuris, M. A., Z. Ra'anan, A. Sagi, and D. Cohen. 1987. Morphotypic differentiation of male Malaysian giant prawn, Macrobrachium rosenbergii. J. Crust. Biol. 7: 219-237.

Landau, M., H. Laufer, and E. Homola. 1989. Control of methyl farnesoate synthesis in the mandibular organ of the crayfish Procambarus clarkii: evidence for peptide neurohormones with dual functions. Invert. Reprod. Dev. 16: 165-168.
Laufer, H., and D. Borst. 1988 . Juvenile hormone in crustacea. Pp. 305-313 in Endocrinology of Selected Invertebrate Types, Invertebrate Endocrinology, Vol. 2. Alan R Liss, Inc., New York.

Laufer, H., D. Borst, F. C. Baker, C. Carrasco, M. Sinkus, C. C. Reuter, L. W. Tsai, and D. A. Schooley. 1987. The identification of a juvenile hormone-like compound in a crustacean. Science 235: 202205.

Laufer, H., M. Landau, D. Borst, and E. IIomola. 1986. The synthesis and regulation of methyl farnesoate, a new juvenile hormone for crustacean reproduction. Pp. 135-143 in Advances in Invertebrate Reproduction, Vol. 4, M. Porchet, J. C. Andries, and A. Dhainaut, eds. Elsevier Science Publications, Amsterdam.

Le Roux, A. 1968. Description d'organes mandibulaires nouvcaux ches les crustaces decapodes. C. R. Hebd. Acad. Sci. Ser. D. Sci. Nat. 266: 1414-1417.

Mitchell, C. J. 1981. Diapause termination, gonoactivity, and differentiation of host-seeking behaviour from blood feeding behaviour in hibernating Culex tarsalis (Diptera: Culicidae). J. Med. Entomol. 18: 386-394.

Sagi, A., E. Homola, and H. Laufer. 1991. Methyl farnesoate in the prawn Macrobrachium rosenbergii: in vitro synthesis by the mandibular organ and titers in the hemolymph. Comp. Biochem. Physiol. 99B: 879-882.

Spielman, A. 1974. Effects of synthetic juvenile hormone on ovarian diapause of Culex pipiens mosquitoes. J. Med. Entomol. 11: 223 225.

Tessier, G. 1960. Relative growth. Pp. 537-560 in The Physiology of the Crustacea, Vol. 1, T. H. Waterman, ed. Academic Press, New York.

Wigglesworth, V. B. 1970. Insect Hormones. W. H. Freeman, San Francisco. 159 pp. 